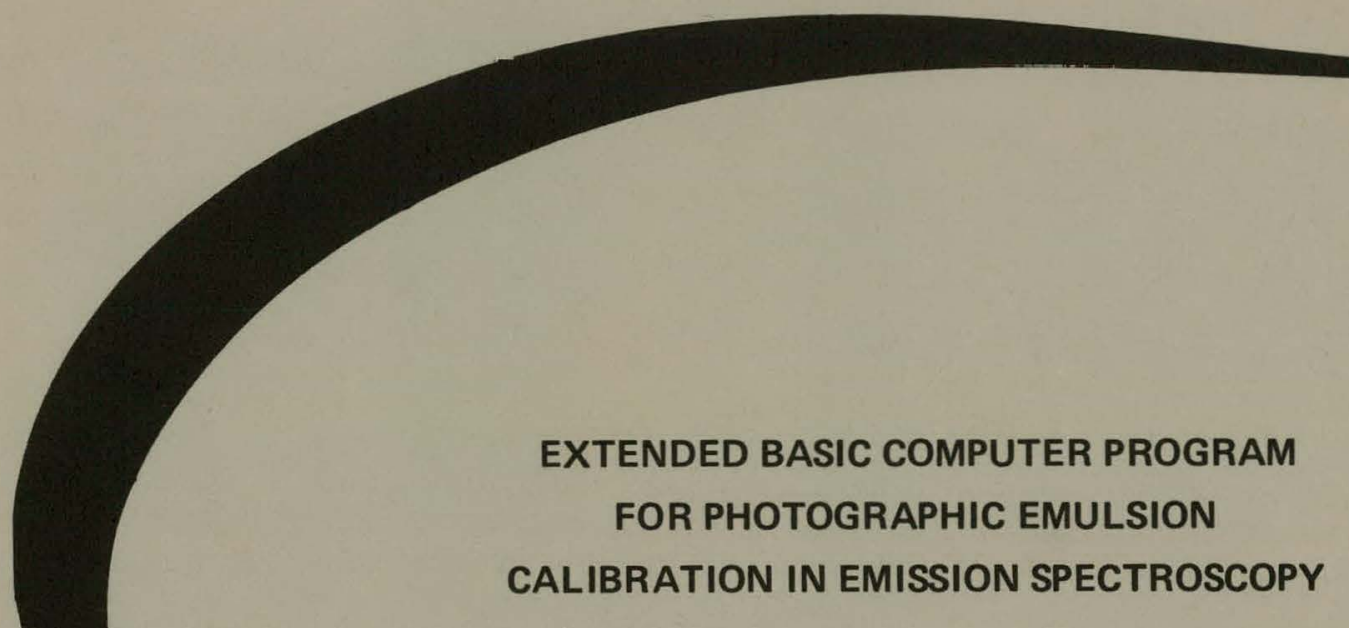

Harlan N. Barton

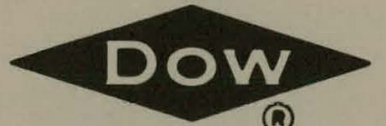

THE DOW CHEMICAL COMPANY ROCKY FLATS DIVISION

P. O. BOX 888

GOLDEN, COLORADO 80401

U.S. ATOMIC ENERGY COMMISSION

CONTRACT AT(29-1)-1106 


\section{DISCLAIMER}

This report was prepared as an account of work sponsored by an agency of the United States Government. Neither the United States Government nor any agency Thereof, nor any of their employees, makes any warranty, express or implied, or assumes any legal liability or responsibility for the accuracy, completeness, or usefulness of any information, apparatus, product, or process disclosed, or represents that its use would not infringe privately owned rights. Reference herein to any specific commercial product, process, or service by trade name, trademark, manufacturer, or otherwise does not necessarily constitute or imply its endorsement, recommendation, or favoring by the United States Government or any agency thereof. The views and opinions of authors expressed herein do not necessarily state or reflect those of the United States Government or any agency thereof. 


\section{DISCLAIMER}

Portions of this document may be illegible in electronic image products. Images are produced from the best available original document. 


\section{LEG A L NOTICE}

This report was prepared as an account of Government sponsored work. Neither the United States, nor the Commission, nor any person acting on behalf of the Commission:

A. Makes any warranty or representation, expressed or implied, with respect to the accuracy, completeness, or usefulness of the information contained in this report, or that the use of any information, apparatus, method, or process disclosed in this report may not infringe privately owned rights; or

B. Assumes any liabilities with respect to the use of, or for damages resulting from the use of any information, apparatus, method, or process disclosed in this report.

As used in the above, "person acting on behalf of the Commission" includes any employee or contractor of the Commission, or employee of such contractor, to the extent that such employee or contractor of the Commission, or employee of such contractor prepares, disseminates, or provides access to, any information pursuant to his employment or contract with the Commission, or his employment with such contractor.

Printed in the United States of America

Available from

Clearinghouse for Federal Scientific and Technical Information

National Bureau of Standards, U. S. Mepartment of Commerce

Springfield, Virginia 22151

Price: Printed Copy $\$ 3.00$; Microfiche $\$ 0.65$ 


\section{EXTENDED BASIC COMPUTER PROGRAM}

FOR PHOTOGRAPHIC EMULSION

\section{CALIBRATION IN EMISSION SPECTROSCOPY}

Harlan N. Barton

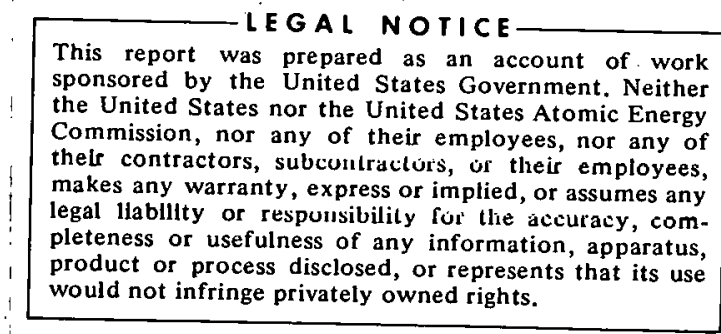

THE DOW CHEMICAL GOMPANY

ROCKY FLATS DIVISION

P. O. BOX 888

GOLDEN, COLORADO 80401

Prepared under Contract AT(29-1)-1106

for the

Albuquerque Operations Office

U. S. Atomic Energy Commission 
RFP-1540 


\section{CONTENTS}

Introduction $\ldots \ldots \ldots \ldots \ldots \ldots \ldots \ldots \ldots \ldots$

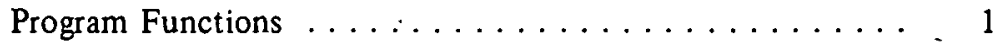

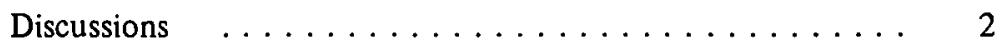

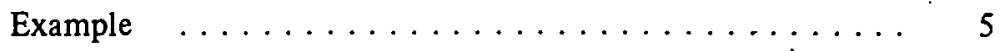

Appendix A CONVER Program. . . . . . . . . . 9

Appendix B Curves Program $\ldots \ldots \ldots \ldots \ldots \ldots \ldots 10$

Appendix C CALCUR Program $\ldots \ldots \ldots \ldots \ldots \ldots \ldots 11$

Appendix D CALTAB Program $\ldots \ldots \ldots \ldots \ldots \ldots \ldots 12$ 
RFP-1540 


\title{
EXTENDED BASIC COMPUTER PROGRAM FOR PHOTOGRAPHIC EMULSION CALIBRATION IN EMISSION SPECTROSCOPY
}

\author{
Harlan N. Barton
}

\begin{abstract}
This series of programs, written in Extended Basic for a time-sharing computer, derives a polynomial representing the Seidel emulsion calibration curve and utilizes this expression in the conversion of analytical line transmittances to relative intensities. An installation library least-squares polynomial curve fitting program is applied in determining polynomial coefficients for both the Seidel preliminary and emulsion calibration curves.
\end{abstract}

\section{INTRODUCTION:}

The graphical derivation of an emulsion calibration curve is tedious and often inaccurate because of the large number of points to be plotted and the fallibility of fitting the preliminary curve by hand. A computer program representing the calibration curve by a number of linear line segments gives improved speed in application but requires considerable preparation and lacks flexibility for ready adaptation to new data of different emulsions and wavelengths.

This group of programs provides an emulsion calibration from the entry of calibration spectra transmittance data. User performed operations consist only of appropriate merging of subprograms. Data in a form convenient for plotting the preliminary curve as Seidel functions and the Seidel emulsion calibration curve are printed for graphical verification if desired.

Conversion of analytical line transmittances to intensities is accomplished by the final program after entry of the calibration constants for the specific emulsion.

\section{PROGRAM FUNCTIONS}

This series of programs performs the computations necessary to derive an expression for the emulsion calibration curve from the transmittance data of the calibration exposures, and uses this expression for experimental data conversion. The functions of the individual programs in the order of their use are:
CONVER: Convert transmittance data of emulsion calibration spectra to Seidel functions.

SEIFIL: Temporary storage of Seidel data of CONVER prior to merger with POLFIT***. Designation of AHOLD as file for POLFIT ${ }^{* * *}$ derived coefficients.

FILIT: Instructions to file polynomial coefficients for Seidel preliminary curve derived in POLFIT***.

POLFIT***: Determine coefficients for polynomial fitting of Seidel function preliminary curve (A General Electric installation library program).

AHOLD: Temporary storage of polynomial coefficients for Seidel preliminary curve derived in POLFIT**** prior to merger with CURVES.

CURVES: Determine successive Seidel functions related by intensity ratio of calibration exposures and file Seidel functions and corresponding logarithm intensities in CALFIL. Present data for optional plot of preliminary and calibration curves.

CALFIL: Temporary storage of Seidel function and log intensity values derived in CURVES prior to merger with POLFIT***. Designation of BEHOLD as file for POLFIT ${ }^{* * *}$ derived coefficients.

FILIT: (Second Usage.) Instructions to file polynomial coefficients for Seidel emulsion calibration curve derived in POLFIT $* * *$ to BEHOLD.

POLFIT***: (Second Usage.) Determine coefficients for polynomial representing Seidel emulsion calibration curve.

BEHOLD: Temporary storage of polynomial coefficients for Seidel emulsion calibration curve derived in POLFIT*** prior to merger with CALCUR and CALTAB.

CALCUR: Convert transmittance of analytical lines to intensity. After entry of coefficients, rename for specific calibration and save.

CALTAB: Produce table of intensities as a function of transmittance for specific calibration. 


\section{DISCUSSION:}

The two-step preliminary curve method of photographic emulsion calibration is the basis for these calculations. ${ }^{1}$ Calibration exposures of an iron arc utilizing a rotating step sector at the slit of a stigmatic spectrograph yield spectral lines of two steps, representative of intensities of unity and the step sector ratio (1.585).

Percent transmittances $T$, are converted to Seidel functions $\Delta$, by

$$
\Delta=\log \left(\frac{100}{T}-1\right)
$$

to give a near linear Preliminary Curve relating the weak segment Seidel function $\Delta_{W}$, to the strong, $\Delta_{S}$. See Figure 1 for an example plot of emulsion calibration data and the computer derived curve.

Points for plotting a continuous curve relating : intensity and percent transmittance, or functions

Figure 1. Preliminary Curve

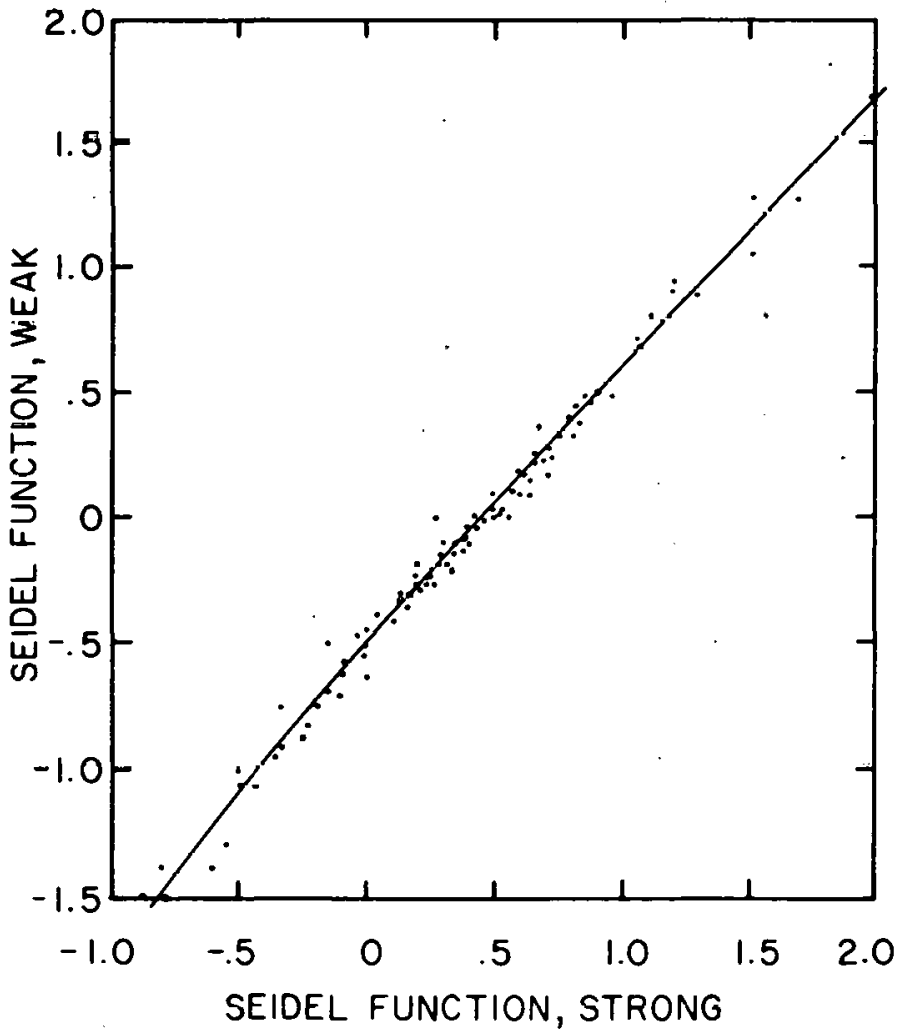

thereor, are obtained by stepping the preliminary curve to obtain a series of Seidel functions related by an intensity ratio of 1.585 as shown in Figure 2.

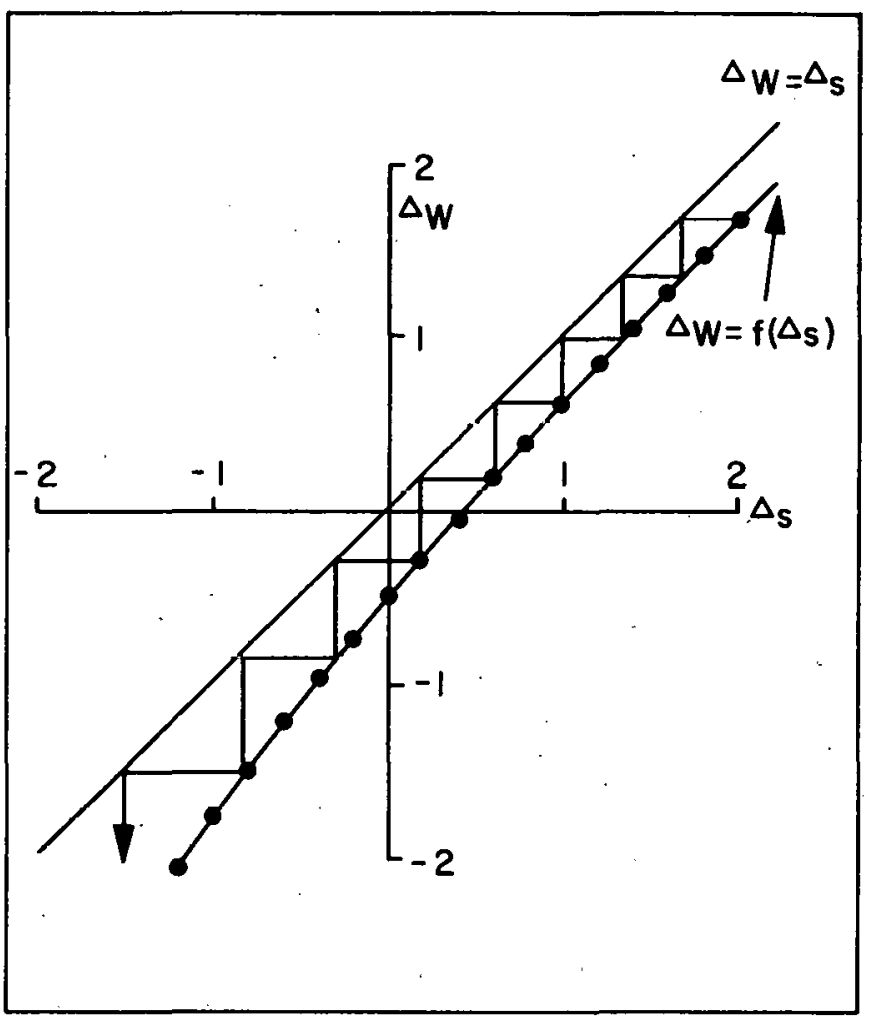

Figure 2. Stepping of Preliminary Curve

The initial Seidel function point $\Delta_{S(1)}$ is selected at the highest reliable point of interest (2. $n$ in the example) and $\Delta_{W(1)}$ is detcrmined from the preliminary curve (1.668 in the example). The succeeding $\Delta \mathrm{S}(2)$ is assigned the value of $\Delta_{W(1)}$, and $\Delta_{W(2)}$ is detcrmined from the preliminary curve (1.348). This is continued to ensure inclusion of the entire region of interest (until the next value of $\Delta_{W}<2.0$ in the example).

The emulsion calibration curve is plotted as the logarithm of intensity versus Seidel function to obtain a near linear relationship (See Figure 3).

User supplied information after entry of the transmittance data of calibration exposures is limited largely to commands merging programs. As shown in Figure 4, filed data in SEIFIL, and filing instructions in FILIT are merged with POLFIT ****. Cuefficients calculated are filed in AHOLD and 


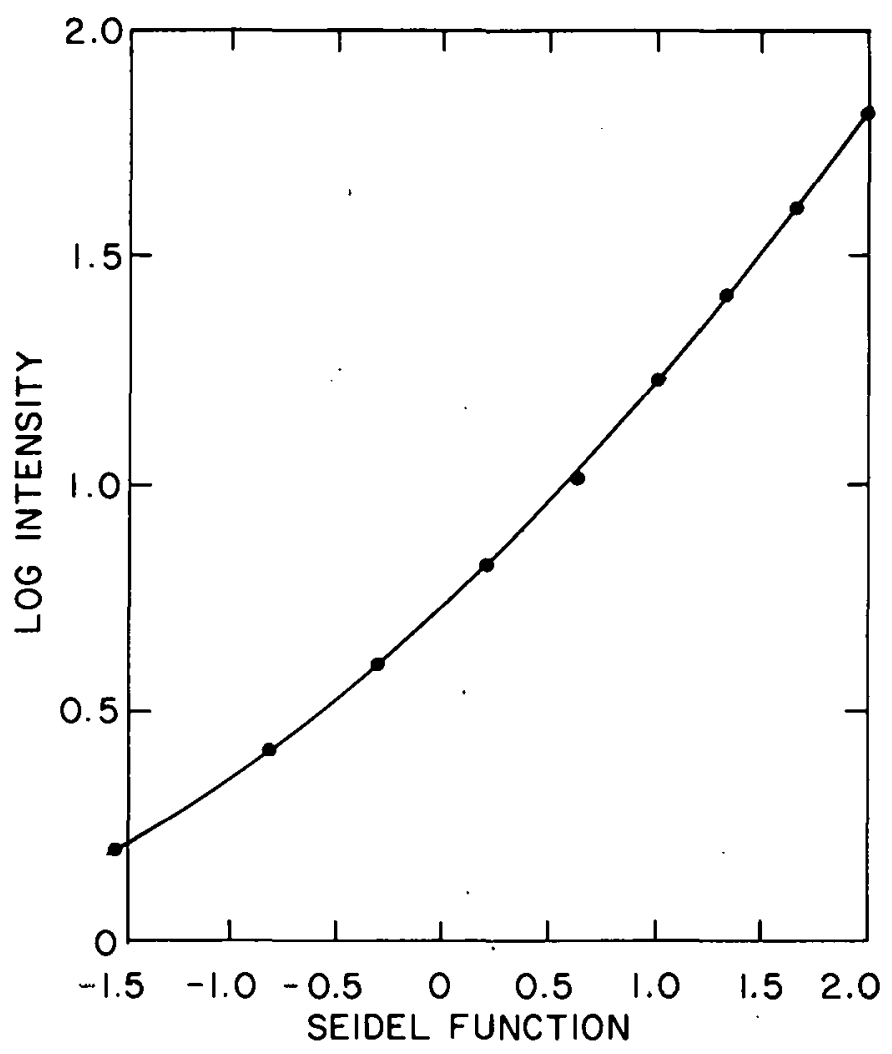

Figure 3. Emulsion Calibration

merged with CURVES. Data calculated in CURVES are filed in CALFIL which along with FILIT is merged with POLFIT***. Coefficients calculated are stored in BEHOLD and merged with CALCUR and CALTAB.

A discussion of the programs in order of use follows:

CONVER: (Appendix A.) This program converts percent transmittances for strong and weak segments of each line determined by a microphotometer of the calibration exposures to Seidel Functions and files these in the temporary program SEIFEL for use in POLFIT***. "T" represents percent transmittance and " $S$ " represents Seidel function defined by $S=\log _{10}(100 / T-1)$. Consecutive line numbers beginning at 100 , and the word "Data" are provided to present the data in a form acceptable to POLFIT***. Percent transmittance data are entered in the order $\mathrm{T}_{(\mathrm{S}) 1}, \mathrm{~T}_{(\mathrm{W}) 1}, \mathrm{~T}(\mathrm{~S}) 2, \mathrm{~T}(\mathrm{~W}) 2, \ldots$

SEIFIL: This temporary program is created and destroyed for each çalibration. Prior to filing data from CONVER, the program contains only: 98 FILES:AHOLD. This designates the program AHOLD to which the succeeding program POLFIT*** will file derived coefficients. After receiving data from CONVER, this program and FILIT are merged with POLFIT***.

FILIT: Modification to the installation library program POLFIT $* * *$ is effected by merger with this program. Instructions for printing to the file program AHOLD specified in SEIFIL are to print successive line numbers beginning at 1000 , the word "DATA", and values for the polynomial coefficients of the Seidel preliminary curve derived by POLFIT***. The program contains the following commands:

$1682 \mathrm{D}=1000$

1683 PRINT \#1, LNM(D); “DATA”; U(J)

Due to the shortness of the program, it is created and destroyed for each calibration.

POLFIT***: (A General Electric time-sharing programming system installation library program.) This program employs a least-squares method of fitting polynomials as high as the eleventh degree to a maximum of 100 data points. Seidel function data stored in SEIFIL is entered as data lines 100 to 299 . The number of points to be fitted, $N$, and the lowest degree polynomial for which information is desired (usually fourth), $\mathrm{D}$, must be entered as data line 010 . The degree of fit and coefficients for the polynomial are part of the print-out. The coefficients are filed to AHOLD as described in the preceeding paragraph. Information on higher degree polynomials is optionally available after the initial selection. The treatment of polynomials other than fourth degree required minor modification to the following CURVES program.

AHOLD: This temporary program, created and destroyed for each use, provides file storage for the polynomial coefficients of the Seidel preliminary curve derived in POLFIT***. The program is merged with CURVES to enter the coefficients into that program.

CURVES: (Appendix B.) This program determines successive Seidel functions, beginning at +2.0 and continuing to -2.0 , whose corresponding intensities are related by the step ratio of the rotating sector filter used in the emulsion calibration (1.585). These values along with line numbers, "DATA", and the logarithm of intensity values incremented by $0.2\left(\log _{10} 1.585\right)$, are filed in CALFIL.

Optional graphical plotting of the Seidel preliminary curve is facilitated by a print-out of the strong and weak segments incremented by 0.2 for the strong 


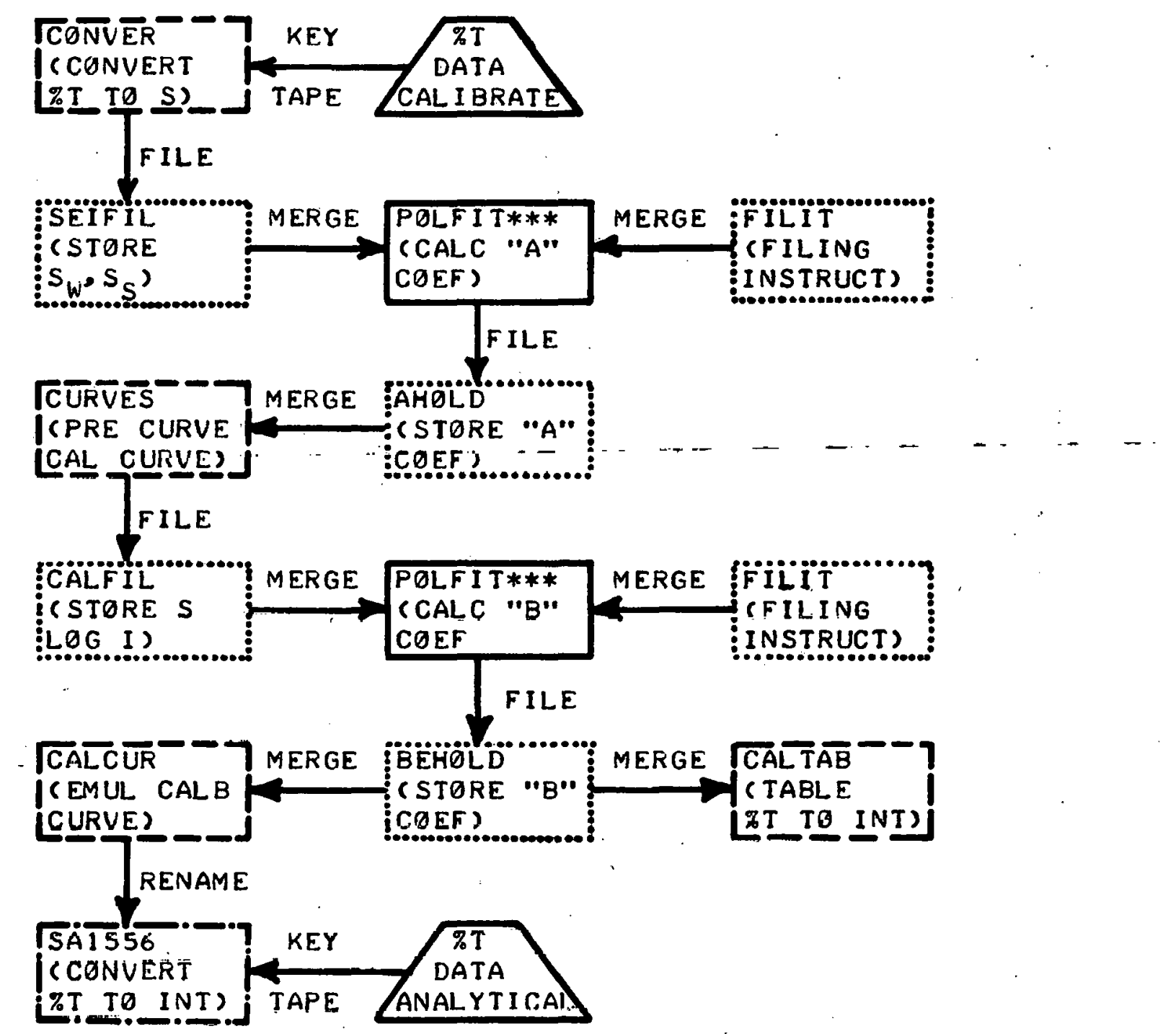

\section{LEGEND:}

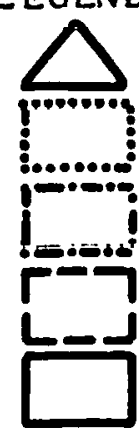

TAPE OR KEY

TEMPORARY PROGRAM

CREATED PREGRAM SAVED

SAVED PROGRAM

INSTALLATION LIBRARY PROGRAM. 
segments. Data for optional plotting of the emulsion calibration curve are provided incremented by $0.2 \mathrm{log}$ intensity. The polynomial coefficients $A(0)$ and $A(4)$ derived in the preceeding POLFIT*** program are entered by merger of AHOLD with CURVES. For polynomials less than fourth degree, zeros should be entered for the missing coefficients. The expression in lines 260 and 390 must be expanded for higher degree polynomials.

CALFIL: This temporary program is created and destroyed for each use. Prior to filing of data from CURVES, the program contains only: 98 FILES: BEHOLD. This designates the program BEHOLD to which the succeeding program POLFIT*** will file derived coefficients. After receiving data from CURVES this program and FILIT are merged with POLFIT ****.

FILIT: Modification to the installation library program POLFIT*** is effected by merger with FILIT as was done previously. Instructions for printing to the file program BEHOLD specified in CALFIL are line numbers beginning at 100, "DATA", and values of the polynomial coefficients of the emulsion calibration curve derived by POLFIT***.

POLFIT***: This second usage of POLFIT*** determines polynomial coefficients $B(0)$ to $B(4)$, for the Seidel emulsion calibration curve and files them in BEHOLD.

CALCUR: (Appendix C.) After receipt of the polynomial coefficients $B(0)$ to $B(4)$, representing the emulsion calibration curve by merger with BEHOLD, the program is renamed to denote the specific calibration and is saved. Percent transmittances of analytical exposures may then he converted to intensities by entry as data line numbers greater than 1004. Print-out consists of the percent transmittance entered and the corresponding intensity.

CALTAB: (Appendix D.) A table of intensities as a function of percent transmittance is generated by this program after entry of the polynomial emulsion calibration coefficients by merger with BEHOLD.

Reference to the table is more convenient than using the CALCUR program when only a few conversions are to be made.

\section{EXAMPLE}

The following is a calibration of a Kodak SAl emulsion at $3000 \mathrm{~A}$ wavelength. One hundred data points were entered in the determination of the preliminary curve.
Throughout this example explanatory material is in the lower case while computer input and print-out are in the upper case. User information entered by keyboard is shown underlined, and is box enclosed when entered by punched tape. It is assumed the following are saved programs: CONVER, CURVES, CALFIL, CALTAB.

1. Create temporary files as follows:

\section{READY \\ NEW:SEIFIL}

READY

98 FILES:AH $\varphi$ LD

READY

NEW:CALFIL

READY

98 FILFS:BFHQLLD

SAVE

READY

NEW:. AH $\varphi$ LD

READY

SAVE

READY

NEW: BEH $\emptyset$ LD

READY

$\underline{\text { SAVE }}$

READY

NEW:FILIT

READY

$1682 \mathrm{D}=1000$

1683 PRINT \#1, LNM(D);“DATA";U(J)

SAVE

2. Enter a maximum of 100 transmittance points from emulsion calibration exposures into old program CONVER: The order of entry is $\mathrm{T}_{(\mathrm{S}) 1}, \mathrm{~T}_{(\mathrm{W}) 1}, \mathrm{~T}_{(\mathrm{S})_{2}, \mathrm{~T}_{(\mathrm{W}) 2}, \ldots}$

$\mathrm{T}_{(\mathrm{S}) 100}, \mathrm{~T}_{(\mathrm{W}) 100}$. Use data lines greater than 999 . Percent transmittances are converted to Seidel functions and filed in SEIFIL.

READY'

$\emptyset$ LD:C $\emptyset$ NVER 
REATYY

TAPE

\section{READY}

1000 DATA $86,97,86,96,80,96,68,89,64,88,59,76,63,87,48,70,19,45,16,35$ 1001 DATA $30,58,28,56,24,48,16,33,20,40,14,32,13,29,16,32,04,08,05,11$ 1002 DATA $06,11,52,75,33,56,34,60,28,52,18,36,06,13,12,25,08,16,88,97$ 1003 DATA 78,95,68,85,55,79,20,44,35,65,21,43,19,41,20,39,06,10,75,92 1004 DATA $31,58,38,66,74,92,49,74,69,90,39,61,35,53,24,47,18,30,43,72$ 1005 DATA $76,91,54,78,58,83,51,76,34,61,10,24,22,47,61,85,56,81,27,53$ 1006 DATA $16,36,16,32,03,08,01,02,31,56,02,05,03,05,56,84,17,37,18,37$ 1007 DATA $32,62,53,81,33,61,34,59,11,24,24,44,23,48,41,70,62,85,39,65$ 1008 DATA $20,40,07,13,08,17,24,47,17,36,28,50,14,28,13,26,27,52,12,25$ 1009 DATA $36,64,12,25,26,65,40,66,39,63,31,56,37,65,38,65,42,67,42,68$ RUN

CQNVER $\quad 13: 37 \quad$ C.S.3. THU.02/26/70

$\emptyset \mathrm{UT} \emptyset \mathrm{F}$ DATA LINE \#110

CQMPUTER UNITS $\quad 12.6$

3. Merge SEIFEL and FILIT with POLFIT**** to enter Seidel function data and instructions for filing coefficients to AH $\emptyset \mathrm{LD}$. Specify EBASIC system. Specify $N$, number of data points and $D$, the degree of polynomial to fit, as data line 010 . Provide responses to computer questions.

\section{READY}

EDIT MERGE PØLFIT***:SEIFEL-96:FILIT-1681

COMPITER UNITS $\quad 07.2$

READY

SYSTEM : F.BASIC

READY

010 DATA 100,1

$\underline{\text { RUN }}$

PQLFIT

13:39 C.S.S. THU.02/26/70

$D \emptyset$ Y $\emptyset \mathrm{U}$ WANT DATA SHIFTED T $\emptyset$ ZER $\emptyset$ MEANS

(1=YES 2=NO)

$? 2$

LEAST-SQUARES P $\emptyset$ LYN $\emptyset$ MIALS

NUMBER $\varphi F$ P $\varphi$ INTS $=100$

MEAN VALUE $\emptyset \mathrm{F} X=.38846$

MEAN VALUE $\emptyset \mathrm{F} Y=-7.53 .574 \mathrm{~F}-2$

STD ERR $\emptyset \mathrm{R} \emptyset \mathrm{F} \mathrm{Y}=.624479$

N $\emptyset$ TE: $C \emptyset D E F \emptyset R$ 'WHAT NEXT?' IS:

$0=$ ST $\emptyset$ P PR $\emptyset \mathrm{GRAM}$

$1=\mathrm{C} \emptyset \mathrm{FFICIENTS} \emptyset \mathrm{NLY}$

$2=$ ENTIRE SUMMARY

3 = FIT NEXT HIGHER DEGREE
POLYFIT $\emptyset$ F DEGREE 4 INDEX $\emptyset F$ DFTFRM $=$ .990925 WHAT NFXT? 1

$\begin{array}{cc}\text { TERM } & \text { CФEFFICIENT } \\ 0 & -.50721461075 \\ 1 & 1.1352727158 \\ 2 & -.04154031744 \\ 3 & .05507442808 \\ 4 & -2.3108735076 \mathrm{E}-2\end{array}$

WHAT NEXT? $\underline{0}$

CQMPUTER UNITS 25.1

4. Merge $A H \emptyset L D$ with CURVES to enter preliminary curve polynomial coefficients. Seidel function and logarithm of intensity data for the emulsion calibration curve will be filed to CALFIL. Data for optional plots of preliminary and emulsion calihration curves will be printed out.

READY

EDIT MERGE CURVES: AH $\emptyset$ LD - 999

CǾMPUTER UNITS - 02.6

READY

RUN

CURVES ' $13: 42 \quad$ C.S.S. $\quad$ THU.02/26/70

DATA F $\emptyset R$ PL $\emptyset T$ T F PRELIMINARY EMULSION CALIBRATI $\emptyset N$ CURVE AS SEIDEL FUNCTIQN

\begin{tabular}{|c|c|}
\hline $\mathrm{X}$ & $\mathrm{Y}$ \\
\hline SEIDEL & SEIDE \\
\hline FUNCT, & FUNC \\
\hline STR $\emptyset \mathrm{NG}$ & WEA \\
\hline$\therefore .0$ & -3.75 \\
\hline-1.8 & .3 .25 \\
\hline-1.6 & -2.81 \\
\hline-1.4 & .2 .42 \\
\hline-1.2 & -2.07 \\
\hline-1.0 & -1.76 \\
\hline-0.8 & -1.48 \\
\hline .0 .6 & -1.22 \\
\hline .0 .4 & -0.97 \\
\hline-0.2 & -0.74 \\
\hline 0.0 & -0.51 \\
\hline 0.2 & .0 .28 \\
\hline 0.4 & -0.06 \\
\hline 0.6 & 0.17 \\
\hline 0.8 & 0.39 \\
\hline 1.0 & 0.62 \\
\hline 1.2 & 0.84 \\
\hline 1.4 & 1.06 \\
\hline 1.6 & 1.28 \\
\hline 1.8 & 1.48 \\
\hline 2.0 & 1.67 \\
\hline
\end{tabular}


RFP-1540.

DATA FØR PLФT OF SEIDEL EMULSI $\emptyset N$

CALIBRATI $\emptyset$ N CURVE

$\begin{array}{ccc} & \text { S } & \text { L } Q \text { G I } \\ 1 & 2.000 & 1.8 \\ 2 & 1.668 & 1.6 \\ 3 & 1.348 & 1.4 \\ 4 & 1.006 & 1.2 \\ 5 & 0.625 & 1.0 \\ 6 & 0.196 & 0.8 \\ 7 & -0.286 & 0.6 \\ 8 & -0.837 & 0.4 \\ 9 & -1.530 & 0.2\end{array}$

\section{C $\emptyset$ MPUTER UNITS $\quad 08.1$}

5. Merge CALFIL and FILIT with POLFIT*** to enter Seidel functions and corresponding intensities, and to provide instructions for filing derived coefficients for emulsion calibration curve to $B E H \emptyset L D$. Specify EBASIC systcm. Specify N, the number of data points read from above print-out (9) and $D$, the degree of polynomial (4) as data line 010 . Provide responses to computer questions.

\section{READY}

EDIT MERGE PQLFIT***:CALFIL-96:FILIT-1681

CØMPUTER UNITS $\quad 05.5$
READY

SYSTEM:EBASIC

READY

O10 DATA 9,4

RUN

$\begin{array}{lll}\text { PØLFIT } & 13: 44 \quad \text { C.S.S. } & \text { THU } 02 / 26 / 70\end{array}$

D $\emptyset$ Y $\emptyset$ U WANT DATA SHIFTED T $\emptyset$ ZER $\emptyset$ MEANS

$(1=\mathrm{YES} 2=\mathrm{N} \emptyset)$

LEAST-SQUARESP $\emptyset$ LYN $\emptyset$ MIALS

NUUMBERE $\not F$ PUIINTS $=9$

MEAN VALUE $\emptyset \mathrm{F} X=.465582$

MEAN VALUE $\varphi \mathrm{F} \mathrm{Y}=1$. STD ERR $\emptyset \mathrm{R} \emptyset \mathrm{F} Y=.547723$

N $\emptyset$ TE: C $\emptyset$ DE F $\emptyset$ R 'WHAT NEXT? IS:

$$
\begin{aligned}
& 0=\text { ST } \varphi \text { P PR } \varphi \text { GRAM } \\
& 1=\text { C } \emptyset \text { EFFICIENTS } \emptyset \text { NLY } \\
& 2=\text { ENTIRE PR } \emptyset \text { GRAM } \\
& 3=\text { FIT NEXT HIGHER DEGREE }
\end{aligned}
$$

P $\emptyset$ LYFIT $\emptyset$ F DEGREE 4 INDEX $\emptyset$ F DETERM $=$

$\begin{array}{cc}.999962 & \text { WHAT NEXT } \\ \text { TERM } & \text { C } \emptyset \text { EFFICIENT } \\ 0 & .71200085663 \\ 1 & .42166266085 \\ 2 & .06729633176 \\ 3 & 2.8035695038 \mathrm{E}-3 \\ 4 & -2.7683091761 \mathrm{E}-3 \\ & \\ & \text { WHAT NEXT ? } 0\end{array}$

C $\emptyset$ MPUTER UNITS $\quad 09.6$

6. Merge BEH $\emptyset$ LD with CALCUR to enter emulsion calibration curve coefficients. Rename and save. Program is ready for conversion of percent transmittance to intensity.

READY

EDIT MERGE CALCUR: BEH $\emptyset$ LD-999

CØMPUTER UNITS $\quad 02.7$

READY

RENAME:SA1556

READY

SAVE

7. Merge BEH $\emptyset$ LD with CALTAB to provide table of intensity as a function of percent transmittance (only beginning and end of table is shown here for brevity).

READY

EDIT MERGE CALTAB:BEH $\emptyset$ LD-999

CØMPUTER UNITS $\quad 02.5$

READY

$\underline{\text { RUN }}$

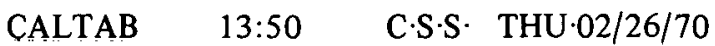

C $\emptyset$ NVERSION \%T T $\emptyset$ INTENSITY,..CALIB $\ldots, \ldots . . . A$

$\begin{array}{rrrrrrrrrrr}\text { \%T } & 0.0 & 0.1 & 0.2 & 0.3 & 0.4 & 0.5 & 0.6 & 0.7 & 0.8 & 0.9 \\ & & & & & & & & & & \\ 1 & 63.08 & 59.34 & 56.12 & 53.32 & 50.85 & 48.66 & 46.70 & 44.94 & 43.34 & 41.88 \\ 2 & 40.54 & 39.31 & 38.17 & 37.12 & 36.14 & 35.22 & 34.36 & 33.56 & 32.81 & 32.09 \\ 3 & 31.42 & 30.78 & 30.18 & 29.61 & 29.06 & 28.54 & 28.05 & 27.57 & 27.12 & 26.69 \\ & & & & & & & & & & \\ 98 & 1.43 & 1.41 & 1.39 & 1.37 & 1.34 & 1.32 & 1.30 & 1.27 & 1.24 & 1.21 \\ \text { yy } & 1.18 & 1.15 & 1.11 & 1.01 & 1.02 & 0.97 & 0.91 & 0.83 & 0.73 & 0.97\end{array}$

CØMPUTER UNITS $\quad 02.5$

8. Unsave the temporary programs to clear for future use and avoid charges for saving.

READY

UNSAVE:SEIFIL

READY

UNSAVE:CALFIL 
RFP-1540

READY

UNSAVE:AHధLD

READY

UNS $\Lambda$ VE:BEH $\emptyset$ LD

READY

UNSAVE:FILIT

9. Conversion of percent transmittance data to intensity is accomplished by recall of saved specific emulsion calibration program and entry of $\% \mathrm{~T}$ data.

READY

$\emptyset \mathrm{LD}: \mathrm{SA} 1556$

READY

2000 DATA $19.7,14.2,12.8,10.0,10.8,09.3$

RUN

SA1556 13:52 C.S.S. $\quad$ THU.02/26/70
CØNVERSI $\emptyset N$ PERCENT TRANSMITTANCE T $\emptyset$ INTENSITY

$\begin{array}{cc}\text { \%T } & \text { I } \\ 19.7 & 9.88 \\ 14.2 & 12.10 \\ 12.8 & 12.89 \\ 10.0 & 14.99 \\ 10.8 & 14.30 \\ 9.3 & 15.67\end{array}$

$\emptyset$ UT $\emptyset$ F DATA LINE \# 170

CØMPUTER UNITS 01.3

\section{REFERENCE}

1. American Socicty for Testing Materials, "Methuds fur Emission Spectrochemical Analysis," 5th Edition, pp. 148-151 (1968). 
APPENDIX A.

CONVER PROGRAM

100 FILES: SEIFIL

110 READ T

$120 S=C L G(100 / T-1)$

$130 \quad I=100$

140 PRINT \#1,LNM(I),"DATA"'S

150 GO TO 110

9999 END 
APPENDIX B.

\section{CURVES PROGRAM}

100 FILES:CALFIL

110 PRINT"DATA FOR PLOT OF PRELIMINARY EMULSION CALIBRATION CURVE" 120 PRINT"AS SEIDEL FUNCTION"

$130^{\circ}$ ENTER VALUES FOR A(0)-A(4) AS DATA LINES 1000-1004

140 PRINT

150 PRINT USING 160

$1608 X \quad Y$

170 PRINT USING 180

180:SEIDEL SEIDEL

190 PRINT USING 200

200:FUNCT • FUNCT.

210 PRINT USING 220

220: STRONG WEAK

230 PRINT

240 READ $A(0), A(1), A(2), A(3), A(4)$

$250 F \oslash R \quad X=-2$ TO 2 STEP. 2

$260 Y=A(0)+A(1) * X+A(2) * X+2+A(3) * X+3+A(4) * X+4$

270 PRINT USING $280, X, Y$

280: \#\#.\# \#\#\#\#

290 NEXT $X$

300 PRINT

310 PRINT"DATA FOR PLOT OF SEIDEL EMULSION CALIBRATION CURVE"

320 PRINT

330 PRINT USING 340

340: $S$ LOG I

$350 \quad x=2$

$360 \mathrm{~K}=1$

$370 I=100$

$38 \overline{8} \bar{Z}=2$

$390 Y=A(0)+A(1) * X+A(2) * X+2+A(3) * X+3+A(4) * X+4$

$400 \quad Z=Z-.2$

410 PKINT 1 , LNM $(I)$, "DATA" $3 \times 3 Z$

420 PRINT USING $430, L N M(K), X, Z$

$430:$ \#\# \#\#\#\#\#..\#

$440 . X=Y$

450 IF $X>-2$ THEN 390

9999 END 
APPENDIX C.

CALCUR PROGRAM

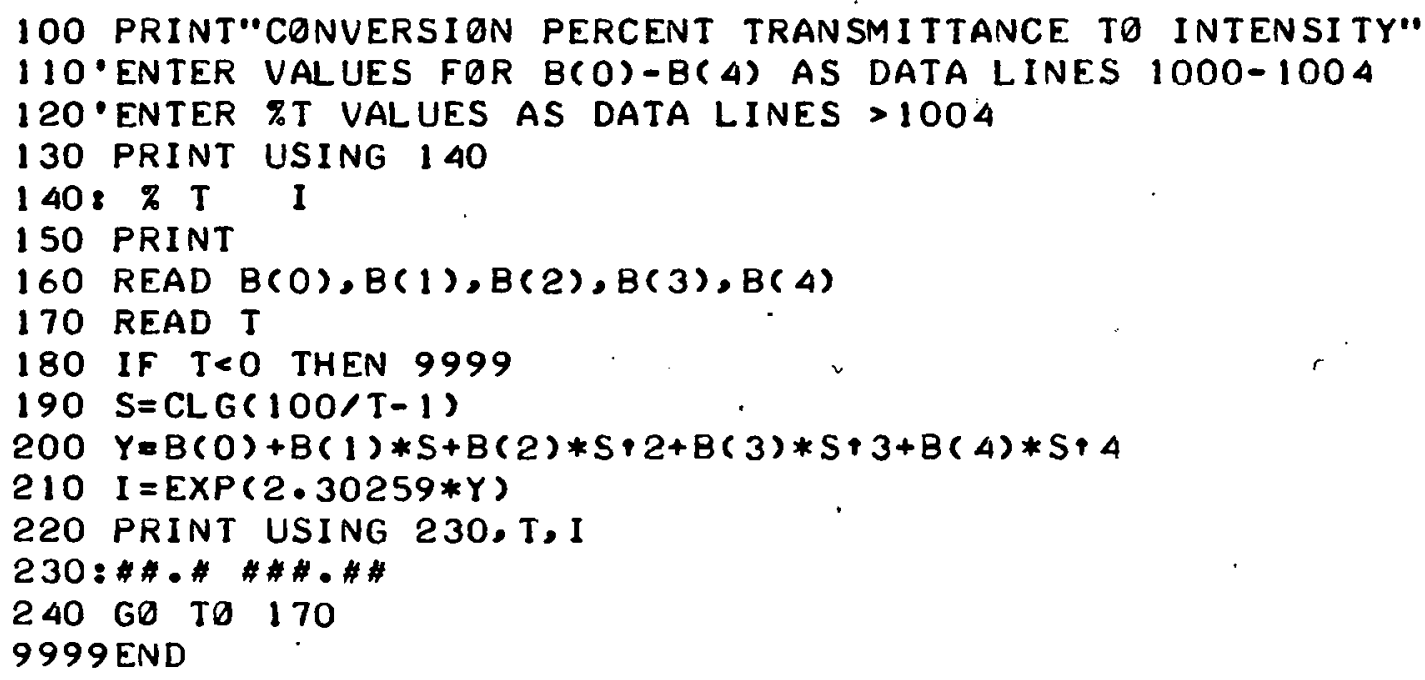


APPENDIX D.

\section{CALTAB PROGRAM}

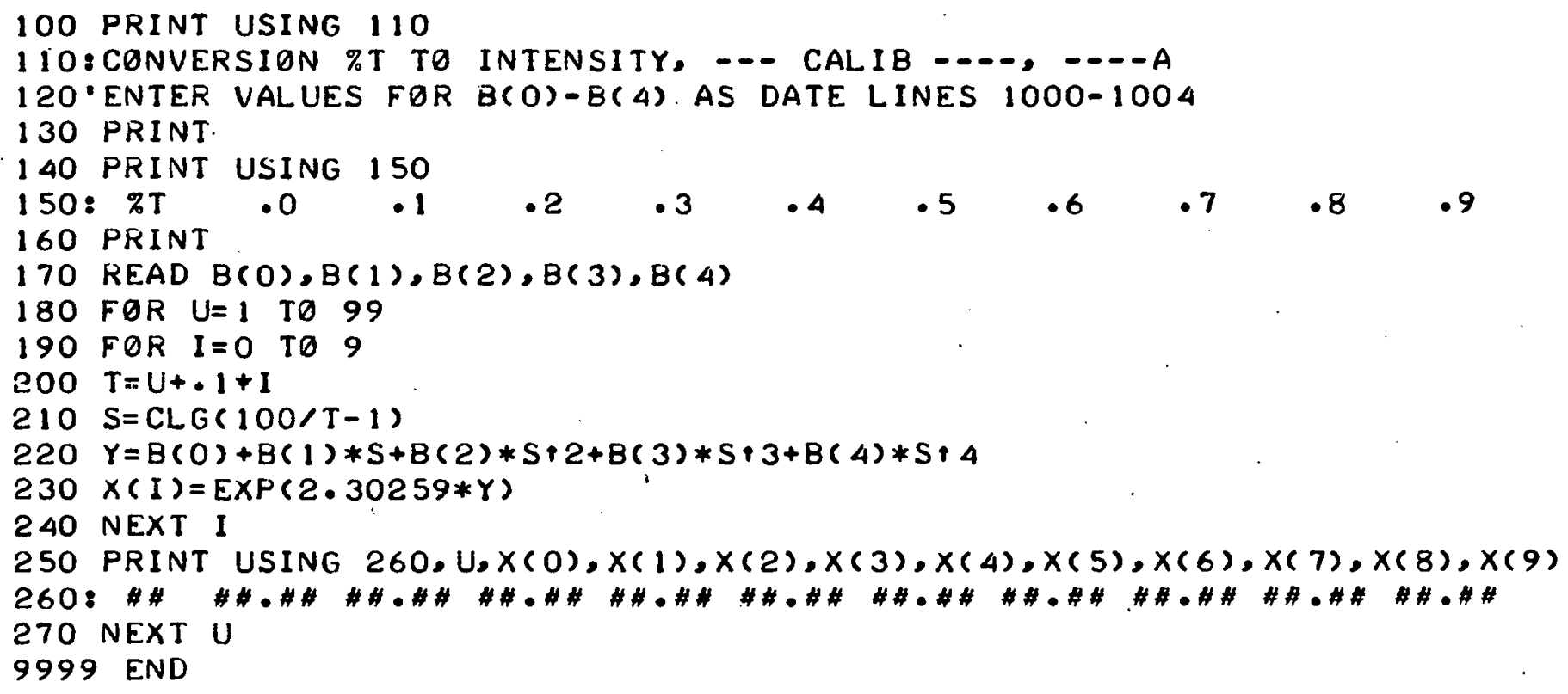

